\title{
Papers
}

\section{Managing event-driven customer relationships in telecommunications}

Received (in revised form): 4th July, 2008

\section{Evangelos Xevelonakis}

is Managing Director of the consulting company Swiss Valuenet and Professor of Business Engineering at the Zurich University of Applied Science. He holds a graduate degree in economics and business information technology and a doctorate in customer relationship management from the University of Zurich. Prof. Dr Xevelonakis, as Senior CRM Advisor, has headed several projects involving customer profitability, campaign management and business intelligence in the telecommunications and banking sectors. Before joining Swiss Valuenet, he headed the Strategic Customer Relationship Management (CRM) Department of Swisscom, where he was in charge of customer segmentation, profitability and business intelligence process. He also worked for Credit Suisse, where he designed and implemented the database marketing process for direct banking. His research interests include predictive modelling for churn and retention management, customer profitability and designing concepts for strategic CRM.

Keywords campaign management, customer relationship management, even driven campaigns, customer lifecycle management, customer value, clustering

\begin{abstract}
Marketing managers in the telecommunication industry are facing a number of business challenges. Despite large investments to retain and to develop customers, high churn rates and decreasing average revenue per user are the result. Often, blanket promotions are deployed, which destroy value through discounts and free services. Frequently, the customer lifecycle approach is ignored by offering these services, and therefore the possibility of tailoring relationship strategies to customer behaviour and value is missed. A systematic approach is necessary to plan a campaign and to evaluate its value. Each campaign is a financial investment for the enterprise. If no thorough planning is made, the enterprise risks selecting the wrong target group, the wrong offers and the wrong channel. The aim of this paper is to discuss a systematic approach to plan and carry out a campaign using Business Intelligence methods. First, the time should be identified that the customer recognises a need in order to send the appropriate marketing message. Secondly, the offer has to meet customers' needs and it has to be relevant at the specific time. Thirdly, the right communication channel should be identified based on customer value and needs. Finally, the campaign performance should be improved incrementally through an ongoing measurement of results. A proposed follow-up paper will deal with the implementation aspects of the Event-Driven Relationship Concept and the 'event driven metrics' that can be used to measure the success of a campaign.

Journal of Database Marketing \& Customer Strategy Management (2008) 15, 146-152. doi:10.1057/dbm.2008.12; published online 8 September 2008;
\end{abstract}

Evangelos Xevelonakis

Zurich, Switzerland and University of Crete, Greece. Tel: +41793480560 ; Fax: +41 443502251 e-mail: xevelonakis@ swiss-valuenet.ch

\section{INTRODUCTION}

The telecommunication industry experiences a lot of radical changes, which are driven by market, business and technological forces. High churn rates of more than 20 per cent ${ }^{1}$ and decreasing 
average revenue per user by 15 per cent annually $^{2}$ are the results. Customers are becoming more difficult to speak to and they require multiple communication and distribution channels. The increase in the choice of channels complicates the method of identifying the right channel for the right customer.

Operators have a massive amount of data available. The big business question is how to transform these data into marketing knowledge and this marketing knowledge into marketing actions.

To meet these challenges in the telecommunication environment, a systematic approach is required. This means that the huge amount of customer data has to be analysed in order to identify the most relevant factors that influence customer buying and churn behaviour.

\section{UNDERSTANDING AND DEFINING THE CUSTOMER LIFE CYCLE STRATEGY}

Each customer has his own characteristics, but nevertheless, the behaviour of certain customers is similar. The aim of customer behaviour analysis is to identify customers who have similar behaviour. There are six main factors that influence customer behaviour: competition, convenience, image, price, quality and customer lifecycle triggers. The company has to be aware of these factors and analyse them to be able to plan and carry out efficient campaigns.

\section{Competition}

Over the past 10-20 years, the telecommunication industry has experienced rapid deregulation, changing customer demands and technical innovation. ${ }^{3}$

Customers are the beneficiaries of this intensified competition in many ways: lower price level, special offers, a higher product or service quality and improved customer care.

A competition analysis is a method for identifying competitors and comparing them with one's own company (eg products, quality, prices, location, customers, etc) to find weaknesses and strengths. ${ }^{4}$ For example, a price analysis of different products is an important instrument. If the competitor prices are higher, advertising can use this information to win or retain customers. Other characteristics that influence customer behaviour in a positive way are products of a higher quality or better customer service than the competitors.

\section{Convenience}

Customers' lives are becoming more and more convenient. Some customers use their mobile phones even at home, because it is more convenient this way: they do not need to look for a phone number and they do not have to leave the room, in the case of a fixed network call. If the company can launch a product that takes into account customer convenience (eg the price for a mobile call is the same as in the case of fixed network if the customer is at home), then the customer will be satisfied.

Another example is internet banking. Customers can save time if they can pay their bills online. Services like this, which improve customer convenience, can be a cause to change providers if they are not offered.

\section{Image}

The company image is quite important for a campaign's success. Many customers buy products because the company has an image of being innovative or of having high quality or lifestyle-improving products. The company can develop new products and campaigns to strengthen this image.

Depending on the image, they are attractive to certain customer segments.

\section{Price and quality}

Price is one of the most important criteria for customers when they are buying a product or service, especially if they have low buying power. ${ }^{3}$ Buying power can be 
estimated using attributes such as age, nationality, education, location and profession. If the competitors offer similar products for different prices, it is quite likely that customers with lower buying power will decide to buy the cheapest one.

Another criterion is the quality. Quality cannot be compared as easily as price, but it also influences customer behaviour. As a rule, customers agree to pay a higher price as long as they also get a higher quality product.

\section{Customer lifecycle triggers}

There are different stages in the customer lifecycle that describe the economic relationship between a customer and the enterprise. ${ }^{5}$ Prospects are potential customers but are not customers yet. New customers have accepted our offer and the company's aim should be to transform them into established customers. Established customers must be retained in order to ensure profitability. Former customers have churned. The business question is what the churn reasons were and which customer is worth winning back.

The customer lifecycle stages are influenced of many events (triggers). Based on customer data analysis, the event-driven relationship approach can be implemented (see Figure 1). ${ }^{6}$
The idea is to identify the relationshipaltering events or 'moments of truth' for the customer. These events affect the requirements and expectations of specific customers. Moving to a new house, children getting older and celebrating birthdays are some examples of events that change customer expectations. Events related to customer behaviour arise from the relationship that customers have with the operator. Examples include approaching the end of a contact period, changes in rate plans and dropping a product or service. External triggers can affect the customer as well. These events occur in the general market. Examples may include seasonal workloads and seasonal holiday periods. Sometimes these data are not available to the operator. ${ }^{7}$ In these cases, proxy information must be used.

The customer lifecycle directly affects long-term customer value. ${ }^{8}$

Basically, there are three ways to increase the value of a customer:

- Cross up selling: Trying to sell more products or products with a higher margin

- Increasing usage

— Keeping customers longer

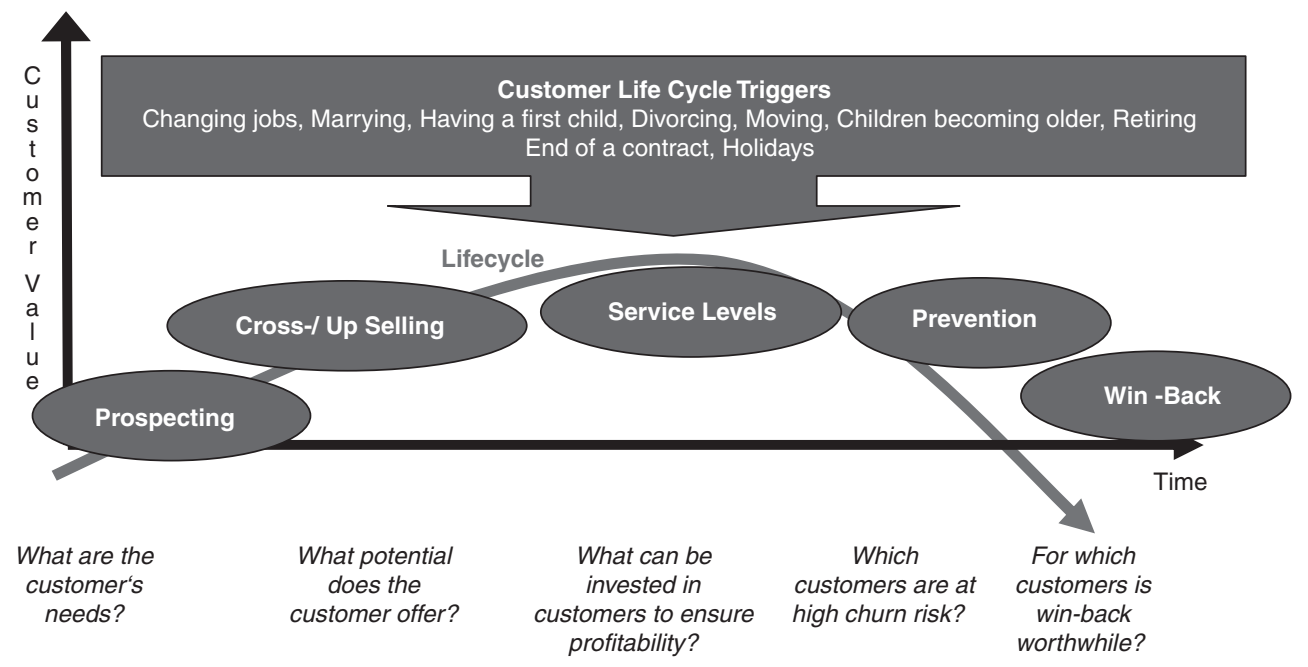

Figure 1: Event-driven relationship management 


\section{DESIGNING THE CAMPAIGN}

The first steps are the definition of the target group (eg unprofitable customers) and the aim (eg increase turnover or sell new products) of the campaign.

Figure 2 shows the return (eg turnover or contribution margin) and the risk (eg churn risk) of customers. A campaign could aim for customers who are in a certain domain of this area, for instance unprofitable customers (C). The aim of the campaign could be to change customers' behaviour to make them profitable. This can be achieved by either increasing the return or by reducing their risk. ${ }^{9}$ The return can be increased in different ways, for example, by increasing the number of sold products or by increasing the turnover on existing products. The churn risk can be decreased by binding the customers with fixed-term contracts or by offering a material (eg rebate) or nonmaterial incentive (eg brand image, customer care).

The next step is to obtain more information about the potential target group. In the case of cross-up selling, for example, organisations have to identify the affinity of their customers for acquiring additional products in order to increase their turnover. To be able to understand customer characteristics and behaviour, a method for identifying homogeneous clusters is required.

\section{Identifying clusters}

Clustering is an excellent method for learning more about customer behaviour

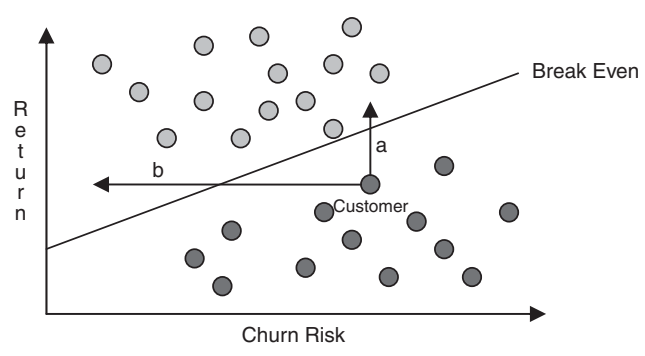

Figure 2: The risk and return of the customers $\mathrm{C}$ and two possible improvements $a$ and $b$ and the characteristics of different types of customers. ${ }^{10}$ A clustering algorithm (eg selforganising maps) maps the customers depending on different attributes on a twodimensional map. Customers with similar attribute values are arranged in proximity to each other, whereas customers with quite different attribute values are arranged in different regions. Several customers who are mapped on the same region can be merged into the same cluster.

The customers' characteristic attributes depend on the business and the purpose of the clustering. Examples of characteristic attributes in telecommunications are as follows:

- Products (fixed networks, mobile, asymmetric digital subscriber line (ADSL), etc)

- Turnover (peak, off peak; national, international, etc)

- Social and demographic information (age, region, language, civil status, nationality, profession, buying power, etc)

The characteristic attributes have to be chosen before the clustering can be started. Only a few of these attributes are selected for the calculation itself, but the other attributes can also be visualised. When the clustering calculation is finished, each cluster represents a customer group with similar attribute values and thus also a similar behaviour.

\section{Set attributes}

The type of attribute can be either value (numbers) or text (characters). For each attribute of type value, the minimum, maximum, arithmetic mean and standard deviation has to be calculated. As the clustering algorithms need numerical input, textual information is not usable for the modelling. Nominal attributes (ie of type text) contain qualitative data (eg gender with values male and female). These nominal attributes have to be converted to 
numerical values by splitting them into dummy attributes.

\section{Examination and transformation of the distribution of attributes}

Data records with missing values or data records that are outliers can be removed from the data set. By applying a transformation, the user can influence the density characteristics of an attribute's distribution. There are two possible transformation types: the Sigmoid and Logarithmic.

Should the records of a specific attribute be mostly concentrated at the left of the histogram while there are fewer records for higher values, the analyst has to make the density distribution more uniform. Applying a logarithmic transformation would equalise the distribution. The logarithmic function gives a higher 'resolution' to small values in the histogram. In the same way, the sigmoid function can lead to a more balanced distribution by stretching the centre of the histogram.

\section{Interpreting the identified clusters}

The clusters are characterised by the customers' attribute averages (eg turnover, the products used, demographic information, etc). Each cluster reveals specific

information. When the result of the clustering is analysed, new knowledge can be gained or assumptions can be verified or discarded. An example: A cluster contains customers whose age is generally lower than the average. Simultaneously, the number of ADSL users is above average. Thus, the conclusion can be made that a lot of ADSL users have a tendency to be younger people and vice versa. Another example concerns the churn. It has been found that there is a high correlation between the churn rate and the bill volatility. Customers with a high volatile monthly bill have a distinctly higher churn rate than those with a low volatile monthly bill. The enterprise could make an offer to these high volatile customers, for example a flat rate product, to lower the monthly volatility and thus also to lower the churn rate.

The different clusters (or parts of a cluster) that comply with the criteria of the target group are now selected and analysed. We are interested in the different customer affinities (eg for communication channels or products). All customers who have a high probability of complying with the aims of our campaign (eg increase turnover or sell new products) are taken into account. In this way, the risk that a campaign will be unprofitable can be minimised. Over time, additional analytics approaches can be used to make campaigns more effective. Modelling the propensity to churn, identifying events or moments of truth, predicting the next best offer and campaign are some examples.

\section{The minimum number of customers needed to obtain a representative result of a campaign test}

After the planning of a campaign, a sample of potential campaign customers is required in order to estimate its effect. The key question is: 'How many customers do we need in the test sample to deliver a result that is representative of the whole population with a certain probability?' Samples should be randomly drawn to ensure an unbiased result. Reliability increases with increased sample size.

\section{Choosing the right communication channel}

A communication channel is a means of interacting with customers. Today's customers have increased expectations and want high quality service. Depending on different customers' profiles, the right communication channel has to be defined.

There are several channels that can be considered. Examples may include e-mail, fax, mail, telephone and the web. The response rate can differ depending on the channel and the customer segment. 
For the first campaign, the identification of the right communication channel is difficult and has to be estimated. Afterwards, the response rate of each channel can be measured and used to improve the channel choice in the next campaign. After several campaigns, the response rate of the different channels and customer clusters are known.

Apart from the affinity for a communication channel, the channel costs also have to be considered (Figure 3). An example: If the customer's affinity for channel A is slightly higher than for channel $\mathrm{B}$, but channel A has higher costs than channel $\mathrm{B}$, then it may be reasonable to use channel $\mathrm{B}$ although the affinity for $\mathrm{A}$ is higher. Another factor also has to be taken into account: the image. Even if, for example, the affinity for e-mail is higher

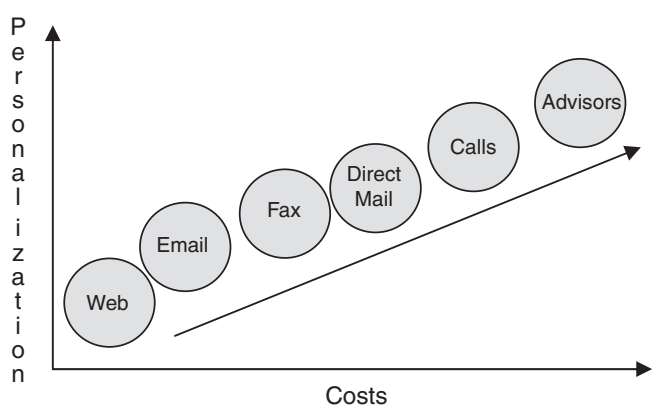

Figure 3: The costs and the customer intimacy for different communication channels than for telephone, the customer may appreciate the more personal contact via telephone. This may increase his contentment and thus also his loyalty.

The communication channel can now be chosen depending on these three factors (affinity, costs and image).

\section{EXECUTING THE CAMPAIGN}

After carrying out a test campaign on a customer sample, the campaign effect should be calculated (eg expected costs, turnover, acquisition of new products, etc). Finally, the decision is made as to whether the campaign should be carried out, depending on the results of these calculations and further considerations. If the decision is positive, an instrument is needed to control the success of the campaign. This is important because each campaign is a financial investment and thus calculations concerning the benefit should be made.

Control groups are the instruments used for the control of the success. A control group is created through a random selection of all potential campaign customers. During and after the campaign, the behaviour of the campaign group and the control group can be compared. The campaign influence is indicated in significantly different customer behaviour (eg the turnover increased or new products were acquired within the campaign group).

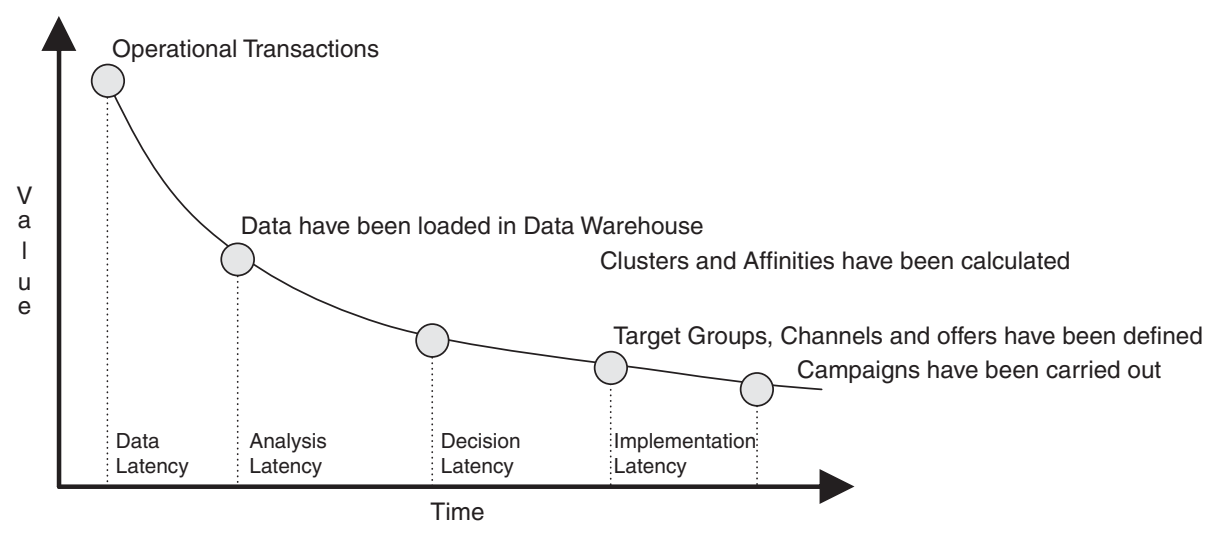

Figure 4: Latency of information (modified adapted from Kemper, Mehanna, Unger, 2006, p.85) 


\section{CRITICAL SUCCESS FACTORS}

A very crucial issue in campaign design is the factor time. It takes time to extract the data. It takes time to build models and make decisions. ${ }^{11}$ Figure 4 shows the loss in value of information due to the latency.

The aim of business intelligence architectures should be to allow the delivery of relevant data as soon as possible to the marketing department, which needs to design near-real-time campaigns. For example, a retention campaign with high data latency could lead to high costs: the targeted customers might have churned at the time of campaign execution.

A very important success factor is to start small and implement the campaign management capabilities incrementally. A cross-functional team has to be created, engaging people from marketing, customer care, IT and product management. ${ }^{12}$

Adapting event-driven relationship management will test many companies but it is a potent way to keep and develop customers and to achieve high profitability.

\section{Reference and Notes}

1 Inside Market Research, June, 2006.

2 Market research and Consulting firm Totel Pty Ltd., 2006.

3 Grant, Ph. (2002) 'Achieving excellent customer relationships', BWCS, Ledbury, UK, pp. 19-24.

4 Hussey, D. and Jenster, P. (2000) 'Competitor analysis, turning intelligence into success’, Wiley, New York.

5 Berry, M. and Linoff, G.S. (2000) 'Mastering data mining', Wiley, New York, pp. 65-90.

6 Xevelonakis, E. (2008) 'Customer relationship management', lecture notes, Zurich University of Applied Science, Zurich.

7 Emagine, Best Practice Campaign Management for Telecommunications Operators, White Paper, April, 2007.

8 Peppers, D. and Rogers, M. (2005) 'Return on customers', Doubleday, New York.

9 Ryals, L. (2002) 'Measuring risk and returns in the customer portfolio', Journal of Database Marketing, Vol. 9, No. 3, pp. 219-227.

10 Xevelonakis, E. (2005) 'Developing retention strategies based on customer profitability in telecommunications: An empirical study', Database Marketing \& Customer Strategy Management, Vol. 12, No. 3, pp. 226-242.

11 Kemper, H. -G., Mehanna, W. and Unger, C. (2006) 'Business intelligence', vieweg, Braunschweig, p. 85.

12 The McKinsey Quarterly, Getting more from prepaid mobile services, February, 2008. 